\title{
Effectiveness of Model Based Training on Competence Regarding Intra Uterine Contraceptive Device (IUCD) Insertion among Nursing Students at Selected Nursing College
}

\author{
Velip Resha Ratnakar $^{1}$, Sunil M. B. ${ }^{2}$, Vani. K. ${ }^{3}$ \\ ${ }^{1}$ Final Year B.Sc. (N), KLES Institute of Nursing Sciences, Hubballi - 580031 (Karnataka), India. \\ ${ }^{2}$ Associate Professor, ${ }^{3}$ Assistant Professor, Department of Community Health Nursing, KLES Institute of \\ Nursing Sciences, Hubballi - 580031 (Karnataka), India.
}

Corresponding Author: Sunil M. B.

\begin{abstract}
Background of the study: Intrauterine contraceptive devices IUCD are a safe and cost-effective contraceptive method. Despite this, the utilisation rate for IUCDs is relatively low in many countries. Provision of training regarding IUCDs to nurses, is one approach to overcome some of the barriers that may prevent wider uptake of IUCDs.

Objectives: To assess the competence of nursing students regarding IUCD insertion. To evaluate the effectiveness of model based training on competence regarding IUCD insertion among nursing students and to find out an association between pre test competence scores of nursing students with their selected socio demographic variables.

Methodology: An evaluative study was conducted among 30 final year B.Sc Nursing students of KLES' Institute of Nursing Sciences, Hubballi. The research design used for the study was Pre-experimental; one group pre-test, post-test design. OSCE based checklist of interval IUCD insertion procedure was used for obtaining the level of competence.

Results: The study results revealed that majority of the subjects $20(66.7 \%)$ were females and $14(46.6 \%)$ had previous knowledge regarding IUCD insertion. With respect to competence scores, majority of the subjects in pre-test $24(80 \%)$ had unsatisfactory competence, $6(20 \%)$ had satisfactory competence. In post-test $25(83.33 \%)$ had satisfactory competence, $05(16.66 \%)$ had unsatisfactory competence. After model based training on competence regarding interval IUCD insertion, there was a significant gain in competence i.e $41.4 \%$. The calculated paired ' $\mathrm{t}$ ' value ( $\mathrm{tcal}=24.44 *$ ) was greater than the tabulated value (ttab $=2.045)$. This indicates that the gain in competence score was statistically significant at 0.05 level of significance.

Conclusion: The study concludes that model based training on competence regarding interval IUCD insertion was effective in upgrading the skills of final year B.Sc nursing students. Hence, it is recommended to re-address $\&$ improve pre-service nursing education pertaining to the family planning services.
\end{abstract}

Key Words: IUCD, competence, OSCE, nursing students, model based training.

\section{INTRODUCTION}

Health is an important factor that contributes to human wellbeing and economic growth. ${ }^{1}$ Being a man or a woman has a significant impact on health, as a result of both biological and gender-related differences. The health of women and girls is of particular concern because, in many societies, they are disadvantaged by many socio-cultural factors. ${ }^{2}$
Universal accesses to sexual and reproductive health services are key priorities and important factors which influence population dynamics. Ensuring that everyone can enjoy the right to 'decide freely and responsibly the number, spacing and timing of their children is essential for women's health and wellbeing, and for overall sustainable development. ${ }^{3}$ 
Studies show India accounts for almost $16 \%$ of the world's maternal deaths (2017 World Health Statistics). Studies also show that abortions alone account for $8 \%$ of total maternal mortalities. Almost $30 \%$ of these deaths can be prevented by increasing access to family planning methods. Further $10 \%$ of child mortality can be prevented, if couples spaced their pregnancies more than 2 years apart. ${ }^{4}$

Family planning allows people to attain their desired number of children and determine the spacing of pregnancies. It is achieved through use of contraceptive methods. ${ }^{5}$

Family planning is one of the most critical components of a health service to ascertain effective sexual, reproductive and maternal health outcomes. Global estimates have shown that effective usage of contraception can prevent $90 \%$ of maternal deaths. This would contribute in achieving the sustainable development goal of reducing the maternal mortality ratio to 70 per 100,000 live births by 2030. 4 There are 214 million women of reproductive age in developing countries who want to avoid pregnancy are not using a modern contraceptive method. ${ }^{5}$

Concerted efforts by the government have resulted in increasing modern contraceptive prevalence from $36.5 \%$ (NFHS I) to $47.8 \%$ (NFHS IV), however $12.9 \%$ (NFHS IV) of eligible couples still have an unmet need for contraception. Approximately 1.2 crore births $(48.1 \%)$ (SRS 2016) annually are inadequately spaced resulting in increased risk of maternal and infant morbidities and mortalities. Studies also highlights that if over the next five years the unmet need for family planning is met globally, the maternal mortality would reduce by $25 \%$ $35 \%$ and further one in every two abortion related deaths would be averted. Ensuring healthy timing and spacing of pregnancies is now considered as one of the most important intervention under $\mathrm{RMNCH}+\mathrm{A}$.

It is well accepted now that use of spacing methods of contraception can save women's lives and improve health due to a reduction in unwanted, closely spaced and mistimed pregnancies, thus avoiding pregnancies with higher risks and reducing chances of abortions, many of which may be unsafe. $^{4}$

There are several safe and highly effective methods of birth control available to prevent unintended pregnancy. These include intrauterine contraception, hormonal and barrier methods, and permanent birth control (sterilization). ${ }^{6}$

It is a well-established fact that long acting reversible contraception (LARC) provides an important solution for averting unintended pregnancies. The IUCD is one of the most popular LARC in the world, having a long history dating back to the 1900s. ${ }^{4}$

Globally, IUCD is the second most popular contraceptive method after female sterilization accounting for $13.7 \%$ of modern contraceptive prevalence rate. In India, IUCD was introduced in 1965 under the National Family Planning Programme. Despite increasing the contraceptive choices under the programme, IUCD usage in India witnessed a decline from $2.0 \%$ in NFHS I (1992-93) to $1.5 \%$ in NFHS 4 (2015-16). This indicates the need to improve provider skills. $^{4}$

The intra-uterine contraceptive device (IUCD) provides a very effective, safe and long term yet reversible protection from unwanted pregnancies, thereby being an ideal spacing method which can address the high unmet need for spacing. ${ }^{4}$

Universal access to family planning services requires family planning workforce (doctors, nurses, auxiliary nurse midwives and community health workers) are competent and possess necessary skills to deliver quality family planning services. It has been documented that family planning services remained a neglected area in low and middle-income countries with high unmet need for family planning. For instance, even though the family planning (FP) program was the first national program in India that started in the year 1952, still it 
is the second most populous country in the world. ${ }^{7}$

Barriers that impede access to adequate contraceptives are inadequate knowledge and skills of the service providers about the family planning services and poor quality of in-service trainings and less emphasis on competency and skillbased learning during preservice medical education. ${ }^{7}$

One approach advocated to increase access to IUCDs is through the provision of education and training for healthcare providers to increase their knowledge, skills in providing this method of contraception. IUCD training for healthcare providers contributed to improved positive attitudes towards IUCDs, high rates of successful insertions, low complication rates, and increased provision of IUCDs. ${ }^{8}$

One of the main reasons that IUCD is under-utilized in India is that many health service providers lack accurate, up to date information about it. It is often found that the advantages are understated, the disadvantages tend to be exaggerated and many misconceptions are prevalent in the community and among the providers. The high discontinuation rate is due to problems related to provider's knowledge and skills leading to improper selection of clients, not following recommended steps of insertion, poor counselling and lack of follow up, all resulting in poor quality of services. ${ }^{9}$

Competency of service providers in knowledge and skills is essential for providing quality family planning services, therefore, there is a need to strengthen the capacity of doctors and nursing personnel at all levels. ${ }^{10}$

Despite the importance of FP in population growth, health, and economic growth, for many years FP teaching in nursing education has remained inconsistent and widely varied in terms of extent and quality of acquired knowledge and skills. In clinical practice, these training irregularities are manifested by the failure of programs to impart necessary practical skills to the nursing students in order to enable them to provide quality and evidence based family planning services as graduates. ${ }^{11}$

Lack of competence among nursing students regarding IUCD can be a major obstacle for providing quality family planning services during their practice after completion of the course. So it is important and necessary for training them about IUCD.

Based on the above observations and imminent need the researcher felt the model based training provides the opportunity to learn new procedures and practice and maintain skills without putting patients at risk. Research has found that model based training improves learners' competence and confidence. This model based IUCD training in this present study is designed for nursing students and this training emphasizes on doing, not just knowing and uses competency-based evaluation of performance.

\section{MATERIAL AND METHODS}

Research approach: Evaluative Research Approach.

Research design: Pre-experimental; one group pre-test, post-test design.

Research setting: KLES' Institute of Nursing Sciences, Hubballi.

\section{Population:}

Target Population: B.Sc. Nursing

Students

Accessible Population: 30 Final year B.Sc. Nursing students studying in KLES'

Institute of Nursing Sciences, Hubballi.

\section{Sample and sampling technique:}

Sample: Final year B.Sc. Nursing students studying in KLES' Institute of Nursing Sciences, Hubballi.

Sampling technique: Non-Probability: purposive sampling.

Sample size: 30

\section{Criteria for selection of the sample:}

The criteria for sample selection are mainly depicted under two headings, which 
Velip Resha Ratnakar et.al. Effectiveness of model based training on competence regarding intra uterine contraceptive device (IUCD) insertion among nursing students at selected nursing college.

includes the inclusion and the exclusion criteria.

\section{Inclusion criteria:}

Nursing students who are,

- Studying in final year in KLES' Institute of Nursing Sciences, Hubballi.

- available at the time of data collection

\section{Exclusion criteria:}

Nursing students who,

- are not willing to participate

- were sick during data collection

\section{Selection and development of the tool:}

Based on the objectives of the study, the tool used for research study was Objective structured clinical examination (OSCE) based checklist. The tool was prepared to assess the competence regarding IUCD insertion. The tool was formulated on the basis of the experience of the investigator, review of literature, extensive library search and consultation with experts.

\section{Description of the data collection tool:}

In this study the data collection tools were consisted of 2 parts covering the following areas.

Section I: Socio demographic variables included 8 items such as age, gender, type of family, area of residence, education of father, education of mother, family income and source of information about IUCD insertion.

Section II: Objective structured clinical examination (OSCE) based checklist

This section consists of steps of interval IUCD insertion procedure for obtaining level of competence of final year B.Sc. Nursing Students regarding IUCD insertion. A score value of one (1) was allotted for each satisfactory performance and zero (0) for each unsatisfactory performance.

\section{RESULTS}

\section{Findings related to socio-demographic variables of subjects}

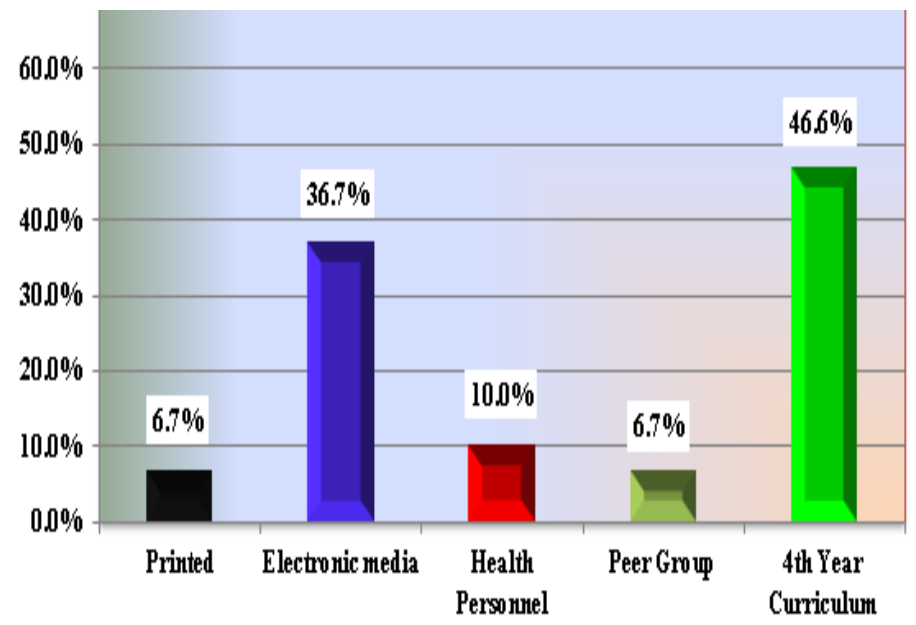

Figure 1: Distribution of subjects according to source of information regarding IUCD insertion

In regard to the age, majority of the subjects $12(40 \%)$ belongs to the age group of 21-22 years and $18(60 \%)$ belongs to the age group of 22-23years. Regarding gender, majority of subjects $20 \quad(66.7 \%)$ were females and $10(33.3 \%)$ were males. In regard to the place of residence, majority of subjects $19(63.3 \%)$ were residing in rural area and $11(36.7 \%)$ were residing in urban area. With regards to family type, majority of subjects $25(83.3 \%)$ were from nuclear family, 05 (16.7\%) from joint family. With regards to the subject's father education, 01 (3.3\%) had no formal education, 11 (36.7\%) had primary education, $09(30 \%)$ had secondary education \& $09(30 \%)$ had 
Velip Resha Ratnakar et.al. Effectiveness of model based training on competence regarding intra uterine contraceptive device (IUCD) insertion among nursing students at selected nursing college.

graduation and above. Regarding subject's mother education, $03(10 \%)$ had no formal education, $12(40 \%)$ had primary education, $10(33.3 \%)$ had secondary education \& 05 $(16.5 \%)$ had graduation and above. With regards to the family's total income per month (in rupees), 08 (26.7\%) had income of Rs. 10,000 \& below, $05(16.5 \%)$ had income between Rs. 10,001 to 20,000, 06 (20\%) had income between Rs. 20,001 to
30,000, 04 (13.4\%) had income between Rs. 30,000 to $40,000 \& 04(13.4 \%)$ had income above Rs. 40,000 \& above. Regarding source of information about IUCD insertion, majority of the subjects $14(46.6 \%)$ had previous knowledge on IUCD insertion from their $4^{\text {th }}$ year curriculum, $11(36.7 \%)$ from electronic media, 03 (10\%) from health personnel \& $02(6.7 \%)$ subjects had previous knowledge from print media.

\section{Analysis and interpretation of competence scores of subjects who have participated in the study regarding IUCD insertion}

Table No 1: Mean, Mode, Standard Deviation and Range of competence scores of subjects regarding IUCD insertion. $\mathbf{n = 3 0}$

\begin{tabular}{|l|l|l|l|l|l|}
\hline Aspects of Analysis & Mean & Median & Mode & Standard deviation & Range \\
\hline Pre-test & 10.50 & 10 & 09 & 2.77 & 11 \\
\hline Post-test & 20.40 & 20.5 & 21 & 1.47 & 06 \\
\hline Difference & 9.9 & 10.5 & 12 & 1.3 & 05 \\
\hline
\end{tabular}

Table No. 1 reveals that the pre-test mean competence score was 10.50 , median 10 , mode 09, standard deviation 2.77 and range 11. Whereas the post-test, mean competence score was 20.40, median 20.5, mode 21, standard deviation 1.47 and range 06 . The overall difference in mean competence score was 9.9, median-10.5, mode-12, standard deviation-1.3 $\&$ range 05 .

Table No 2: Frequency and percentage distribution of competence scores of subjects regarding IUCD insertion. $n=30$

\begin{tabular}{|l|l|l|l|l|}
\hline \multirow{2}{*}{ Level of Competence } & Pre-test & Post-test \\
\cline { 2 - 5 } & Frequency (f) & Percentage (\%) & Frequency (f) & Percentage (\%) \\
\hline Satisfactory (13 and above) & 06 & $20 \%$ & 25 & $83.33 \%$ \\
\hline Unsatisfactory (13 and below) & 24 & $80 \%$ & 05 & $16.66 \%$ \\
\hline
\end{tabular}

Table No 2 shows that distribution of level of competence scores of $4^{\text {th }}$ year B.Sc Nursing students regarding IUCD insertion during pre-test and post-test. Most of the subjects in pre-test $24(80 \%)$ had unsatisfactory competence, $6(20 \%)$ had satisfactory competence. In post-test after model based training on competence, maximum subjects $25(83.33 \%)$ had satisfactory competence, $05(16.66 \%)$ had unsatisfactory competence regarding IUCD insertion.

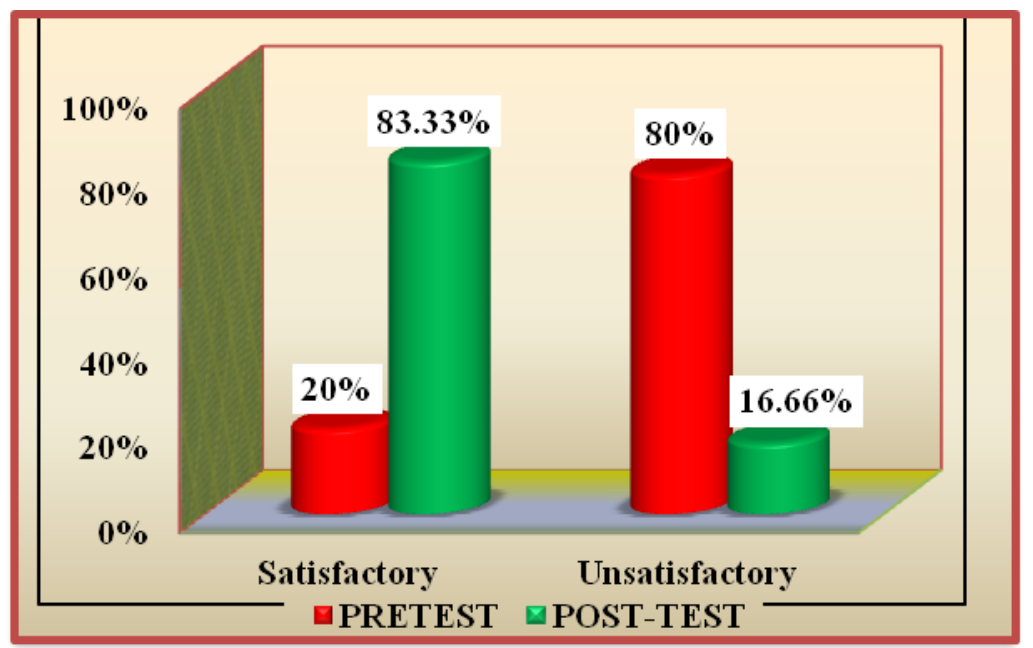

Figure 2: The cylindrical graph represents the percentage distribution of the subjects according to their level of competence scores. 
Velip Resha Ratnakar et.al. Effectiveness of model based training on competence regarding intra uterine contraceptive device (IUCD) insertion among nursing students at selected nursing college.

Table No 3: Pre-test, Post-test percentage of competence scores of subjects regarding IUCD insertion. $\quad$ n=30

\begin{tabular}{|l|l|l|l|l|}
\hline \multirow{2}{*}{ Items } & \multirow{2}{*}{ Total Scores } & \multicolumn{3}{|c|}{ Mean \% competence scores of subjects } \\
\cline { 3 - 5 } & & Pre-test & Post-test & Gain in competence \\
\hline OSCE based checklist & 720 & 43.8 & 85 & 41.4 \\
\hline
\end{tabular}

Table No 3: Reveals that there was $41.4 \%$ gain in competence after model based training on competence regarding interval IUCD insertion.

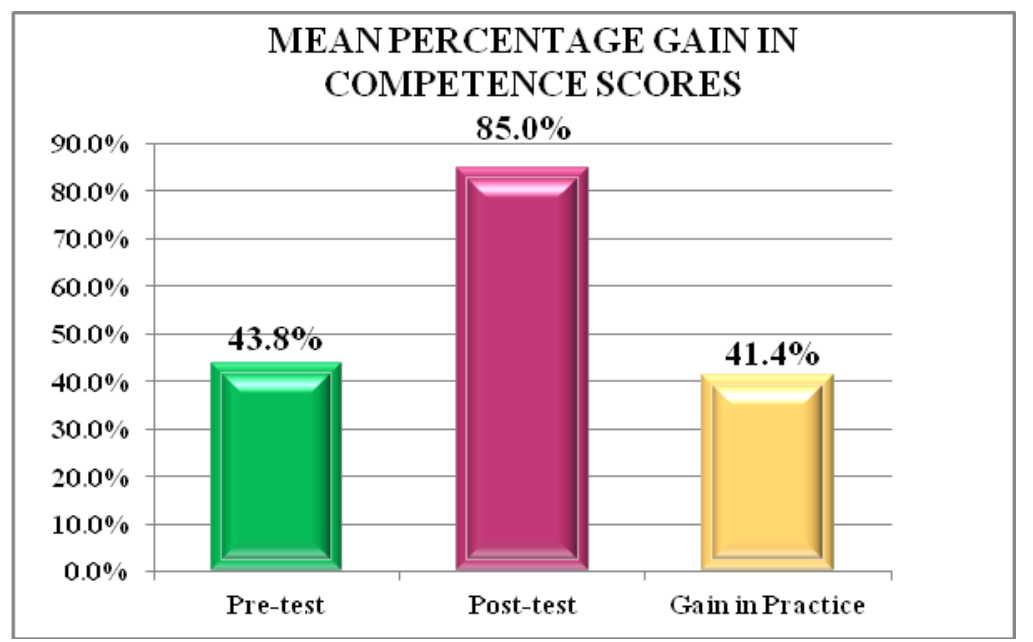

Figure 3: The column graph represents Pre-test, Post-test percentage of competence scores of subjects regarding IUCD insertion.

\section{Testing of hypothesis}

The calculated paired ' $\mathrm{t}$ ' value $\left(\mathrm{t}_{\mathrm{cal}}=\right.$ $\left.24.44^{*}\right)$ was greater than the tabulated value $\left(t_{\text {tab }}=2.045\right)$. This indicates that the gain in competence score was statistically significant at 0.05 level of significance. Therefore, model based training on competence regarding interval IUCD insertion was effective in upgrading the skills of final year B.Sc. Nursing students.

Analysis and interpretation of data to find out an association between pre-test competence scores of subjects with their selected socio demographic variables.

Calculated chi-square value for place of residence 4.3 was greater than tabulated value 3.84 . Hence, there was an association between pretest competence scores of subjects only with their place of residence. And there is no association between pretest competence scores of subjects with their other socio demographic variables like, age, gender, type of family, education of father \& mother, family's total income per month and sources of information about IUCD insertion.

\section{DISCUSSION}

The present study was undertaken to evaluate the effectiveness of model based training on competence regarding Intra Uterine Contraceptive Device (IUCD) insertion among nursing students at selected nursing college, Hubballi. The level of competence scores of $4^{\text {th }}$ year B.Sc. Nursing students regarding IUCD insertion during pre-test and post-test reveals that majority of the subjects in pre-test $24(80 \%)$ had unsatisfactory competence, $6(20 \%)$ had satisfactory competence. In post-test after model based training, majority of the subjects $25(83 \%)$ had satisfactory competence, $03(10 \%)$ had unsatisfactory competence regarding IUCD insertion.

Similar study was conducted by Azra Amerjee, Munazza Aktar, where the majority of them in pre test $72(80 \%)$ had unsatisfactory competence, 18 (20\%) had satisfactory competence. In post test after model based training, majority of the subjects $75(83.3 \%)$ had satisfactory competence, $15(16.6 \%)$ had unsatisfactory competence regarding IUCD insertion. ${ }^{13}$ 
Velip Resha Ratnakar et.al. Effectiveness of model based training on competence regarding intra uterine contraceptive device (IUCD) insertion among nursing students at selected nursing college.

\section{CONCLUSION}

The findings revealed that, out of 30 final year B.Sc Nursing students, majority of the subjects $18(60 \%)$ belong to the age group of 22-23 years. Comparison of pretest and post-test competence scores revealed that the post-test competence score was significantly higher than the pre-test competence scores. There was $41.4 \%$ gain in competence after model based training on competence regarding interval IUCD insertion.

The study concludes that model based training on competence regarding interval IUCD insertion was effective in upgrading the skills of final year B.Sc. nursing students. Hence, it is recommended to re-address \& improve pre-service nursing education pertaining to the family planning services.

\section{Implications Of The Study:}

The findings of the present study have contributions in nursing practice, nursing education, nursing administration and nursing research.

- Findings of the study can be used by the nurse educator to explore the extent and quality of pre-service teaching regarding family planning methods.

- The nurse educator should organize different types of education and training programs for nursing students to improve knowledge and building skills regarding IUCD insertion techniques, counselling skills and other family planning methods by conducting role plays, organizing capacity building seminars and by using simulators.

- With respect to nursing practice, these results have many implications not only in providing quality family planning services at present but also in terms of producing skilled family planning workforce in the future.

- The study results helps the nurse administrator to initiate and carry out various methods of teaching and training for nursing students and nursing officers, regarding IUCD insertion, removal and other skills at various settings.

\section{Recommendations:}

Keeping in the view the findings of the present study, the following recommendations were made:

- Information provided through this study can be considered as a baseline assessment for designing large-scale research studies.

- A similar study can be conducted on post graduate students to assess the competence regarding IUCD insertion.

- It is recommended to re-address IUCD training in pre-service nursing education, based on its current importance to national needs.

- It is recommended to improve the preservice nursing education pertaining to the family planning services.

\section{ACKNOWLEDGEMENT}

It is my pleasure and privilege to express my sincere thanks to Dr. Sanjay. M. Peerapur M.Sc. (N), Ph.D, Principal and HOD of Medical Surgical Nursing, KLE'S Institute of Nursing Sciences, Hubballi for his motivational assistance, valuable suggestions and expert guidance in completing this study successful in spite of his busy schedule.

I would like to express my heartfelt thanks and deep sense of respect to Honorable Vice Chancellor, Registrar and Director, Advanced Research Wing of RGUHS, Bangalore for encouraging us by sanctioning UG Research Grants to conduct this project (UG20NUR430).

The present study has been under the expert guidance, support and encouragement of my teacher and guide $\mathrm{Mr}$. Sunil M.B., M.Sc.(N) Associate Professor and HOD of Community Health Nursing, KLES' Institute of Nursing Sciences, Hubballi. I am greatly to his keen interest, sustained patience and kind co-operation throughout the study. It is indeed an honor and privilege to be guided by him. 
Velip Resha Ratnakar et.al. Effectiveness of model based training on competence regarding intra uterine contraceptive device (IUCD) insertion among nursing students at selected nursing college.

I express my sincere gratitude to Mrs. Vani K., M.Sc.(N) Assistant Professor Community Health Nursing, KLES' Institute of Nursing Sciences, Hubballi for her generous assistance, formation of ideas and thoughts in completing this study successfully.

I feel fortunate to have the endless guidance from all my teachers of KLES' Institute of Nursing Sciences, Hubballi for their timely suggestions, guidance, constant support and help which has proved to be a source of inspiration to me in completing the entire course of the study.

\section{Conflict of Interest: None}

\section{Source of Funding: None}

\section{Ethical Approval: Approved}

\section{REFERENCES}

1. Women's health. [Online], Cited on March 19 2020, [Available from] https://www.nhp.gov.in/healthlyliving/wom en-s-health

2. Women's health. [Online], Cited on March 19 2020, [Available From] https://www.who.int/topics/womens_health/ en/

3. Population Dynamics, Reproductive Health and Sustainable Development: Critical Links and Opportunities for Post-2015. Population and Sustainable Development Alliance. 2015.2 [Available from]https://sustainabledevelopment.un.org/ /getWSDoc.php?id=2753

4. National Health Mission. Reference Manual for IUCD Services. Family Planning Division Ministry of Health and Family Welfare, March 2018.

5. Family planning / Contraception. [Online], 8 February 2018, [Available From] https://www.who.int/news-room/factsheets/detail/family-planning-contraception

6. Women's Reproductive Health [Online], Feb 17, 2017. [Available from]

7. https://www.cdc.gov/reproductivehealth/wo mensrh/index.htm
8. Gupta M, Verma M, Kaur K, Iyengar K, Singh T, Singh A. Competency assessment of the medical interns and nurses and documenting prevailing practices to provide family planning services in teaching hospitals in three states of India. PLoS One $201911 ; 14(11)$.

9. Ouyang $\mathrm{M}$, Peng $\mathrm{K}$, Botfield JR, McGeechan K. Intrauterine contraceptive device training and outcomes for healthcare providers in developed countries: A systematic review. PLoS One. 2019;14(7): e0219746. Published 2019 Jul 15. doi:10.1371/journal.pone.0219746

https://www.ncbi.nlm.nih.gov/pmc/articles/ PMC6629157/

10. IUCD Reference Manual for MOs and Nursing Personnel. [Online] Sept 2018. [Available from]

http://www.nrhmtn.gov.in/modules/IUCD_ Reference_Manual_for_MOs_and_Nursing _Personne_-Final-Sept_2013.pdf

11. Mosadeghrad A. M. (2014). Factors Affecting Medical Service Quality. Iranian journal of public health, 43(2), 210-220. [Available from] https://www.ncbi.nlm.nih.gov/pmc/articles/ PMC4450689/

12. Muganyizi, P.S., Ishengoma, J., Kanama, J. et al. An analysis of pre-service family planning teaching in clinical and nursing education in Tanzania. BMC Med Educ 14, 142 (2014). https://doi.org/10.1186/1472-6920-14-142

13. Khan Azra Amerjee Aga. An effective teaching and learning modality for intrauterine contraceptive device insertion in University Hospital, Karachi simulation training: 2018 January. 31(2):119: Available from:

https://www.researchgate.net/publication/32 9331374.

How to cite this article: Ratnakar VR, Sunil M. B., Vani. K.. Effectiveness of model based training on competence regarding intra uterine contraceptive device (IUCD) insertion among nursing students at selected nursing college. Int J Health Sci Res. 2021; 11(7): 257-264. DOI: https://doi.org/10.52403/ijhsr.20210735 